\title{
Conta Satélite de Turismo no Brasil: método de avaliação do impacto econômico do turismo
}

\author{
Tourism Satellite Account in Brazil: \\ evaluation method of the tourism economic impact
}

\author{
Décio K. Kadota \\ Wilson Abrahão Rabahy ${ }^{2}$
}

\begin{abstract}
RESUMO: Desenvolve os conceitos e os métodos adotados na construção da Conta Satélite do Turismo (CST) no Brasil, de acordo com proposição da OMT - Organização Mundial do Turismo. O artigo é desenvolvido em sete seções, assim descritas: apresentação do problema; evolução dos instrumentos de avaliação do turismo; conceitos básicos na formulação da CST; métodos na elaboração da CST; fontes e restrições de dados; principais resultados alcançados; e conclusōes. Fornece uma avaliação preliminar do impacto do turismo na economia, particularmente no que diz respeito a sua contribuição no PIB do País e na geração de empregos.
\end{abstract}

PALAVRAS-CHAVE: turismo e economia; conta satélite de turismo; conceitos e método de avaliação; impactos econômicos; contribuição no PIB e geração de empregos; Brasil.

\begin{abstract}
The concepts and the methods adopted in the elaboration of the Tourism Satellite Accounts - TSA in Brazil was development according to the proposed by WTC - World Tourism Council. The article is development in 7 (seven) sections, described as: problem approach; evolution of the
\end{abstract}

1. Economista e Professor Doutor da Faculdade de Economia, Administraçāo e Contabilidade da Universidade de Sāo Paulo. Professor do Departamento de Economia da FEA-USP e pesquisador da Fipe. E-mail: dkkadota@usp.br

2. Economista, Professor Titular da Escola de Comunicações e Artes da USP e pesquisador da Fipe.

E-mail: rabahy@usp.br 
evaluation instruments of tourism; basic concepts in the TSA; methods in the elaboration of TSA; sources and restrictions of data information; main reached results; and Conclusions. It supplies preliminary evaluation about the impact of tourism in the economy, particularly on its contribution in the Gross Domestic Product on the country and on the employment market.

KEYWORDS: tourism and economy; tourism satellite account; concepts and method of assessment; economic impacts; contribution to Gross Domestic Product and job creation; Brazil.

\section{Introdução}

Este artigo objetiva descrever o marco conceitual da elaboração da Conta Satélite de Turismo no Brasil - CST, construída pela Fipe para a Embratur, como instrumento de detalhamento de medida dos impactos do turismo nas Contas Nacionais do País, nos moldes preconizados pela Organização Mundial do Turismo - OMT.

A proposição da OMT em desenvolver modelos padronizados de construção da CST para seus países membros é resultado de projetos que vêm se desenvolvendo ao longo do tempo, particularmente a partir da Conferência da Ottawa de 1991, com vistas a dispor de informações fidedignas e consistentes, como suporte a estudos e avaliações do impacto socioeconômico do turismo.

Até recentemente, as estatísticas sobre esta atividade eram incompletas e insuficientes, privando os agentes econômicos de informações essenciais às suas decisões de políticas e de investimentos. Enfatizavam, então, apenas as questões que contribuem para a caracterização dos visitantes e das condições e motivos da viagem. A proposição do método da CST é buscar propiciar informações que contribuam também para uma medida mais acurada e específica do turismo na economia.

O turismo diferencia-se de outros setores de atividade por suas especificidades. O consumo turístico, por exemplo, não se restringe a um particular setor produtivo, nem é, em sua maior parte, efetuado no local do entorno habitual dos consumidores. Apresenta complexas interfaces com outros setores de atividade, merecendo, por isso, um tratamento especial, que permita que se isole a contribuição do turismo no resultado global de produção e do consumo da economia. Uma das soluções propostas é a dada pela OMT, ao preconizar a Conta Satélite do Turismo.

\section{Evolução Histórica dos Instrumentos de Medida dos Impactos Econômicos do Turismo}

A evolução das ações e projetos da OMT, com vistas à avaliação do turismo na economia, pode ser classificada em três fases: a conceituação e classificação das estatísticas do turismo; a estimativa do significado econômico do turismo, a partir das Contas Nacionais; e a proposição de um método específico de avaliação do impacto econômico do turismo, a CST.

\section{Definição e classificação sobre estatísticas do turismo (1937 a 1980)}

- Em 1937, o Conselho da Sociedade das Nações recomendou uma definição de "Turistas Internacionais" para fins estatísticos, que, posteriormente (reunião em Dublin, 1950), foi ligeiramente modificada pela Iuoto (União Internacional de Organizações Oficiais de Viagem).

- Em 1953, a Comissão de Estatísticas da ONU estabelece o conceito de "Visitante Internacional".

- Em 1963, na Conferência da ONU sobre Turismo e Viagens, a Iuoto propõe a distinção dos termos: visitante, turista e excursionista, proposta esta aprovada pela Comissão de Estatística da ONU em 1968.

- Em 1978, a Comissão de Estatística da ONU aprova as diretrizes provisionais dessas estatísticas do Turismo Internacional.

Consolidação da importância dessas estatísticas e sua interdependência com as contas nacionais (década de 1980)

- Em inícios dos anos 80, a OMT propõe modificações de definições e classificação do turismo, com vistas à sua compatibilização e integração às Contas Nacionais.

- Em 1983, a OMT, em encontro em Nova Délhi, apresenta, com dados de 1968, resultados simulados de impactos econômicos do turismo, com vistas a demonstrar ser viável a integração do turismo às Contas Nacionais.

- Em 1991, na Conferência sobre Estatística do Turismo e Viagens, realizada em Ottawa, Canadá, completa-se o ciclo, com a proposição de se desenvolver o sistema de Conta Satélite do Turismo. 


\section{Avanços no método proposto da CST (1991 - 2000)}

- Em 1993, a Comissão de Estatísticas da ONU adota as recomendações propostas pela OMT na Conferência de Ottawa, relativas às definições e classificações uniformes do turismo e sobre a Classificação Internacional Uniforme das Atividades Turísticas (Ciuat).

- Em 1994, a ONU e a OMT publicam um Informe com essas definições. Por seu turno, a OCDE, em 1992, inicia a análise das Contas Econômicas do Turismo, resultando na proposição normativa de 1997.

- Em 1997, o Comitê de Turismo de OCDE apresenta uma primeira proposta da Conta Satélite do Turismo para seus países membros. Assim também a Eurostat (Escritório de Estatísticas da Comunidade Européia).

- Neste período, entre os países que então desenvolveram o sistema de CST, destacam-se o Canadá (1994), a Noruega, a Suécia, os Estados Unidos, a República Dominicana e o México, e a maioria dos países de OCDE, em especial a Súça, a Austrália e a Finlândia.

- Também são destacados os esforços, em nível do setor privado, da WTTC (Conselho Mundial de Viagens e Turismo), embora com metodologia diversa, centrada no lado da demanda, a partir dos gastos dos visitantes.

- No Brasil, por convênio firmado entre a Embratur e a OMT, com o apoio do Programa das Nações Unidas para o Desenvolvimento - PNUD, foram realizados em 1989/90 estudos para a avaliação dos impactos do turismo, que contou com a participação de consultoria técnica da OMT. O projeto de pesquisa consistiu no estabelecimento de um modelo de avaliação dos impactos econômicos do turismo, baseado no Sistema de Contas Nacionais e na Matriz de Insumo-Produto (1980). A partir desses elementos de análise, foram desenvolvidos os cálculos das estimativas da participação relativa do turismo nos principais agregados macroeconômicos do país.

\section{Conceitos Básicos na Formulação da CST}

Um adequado modelo de avaliação dos efeitos socioeconômicos do turismo deve basear-se em um sistema de informações turísticas e conexas, de caráter estatístico e regular, fornecidas por fontes fidedignas; comparáveis no tempo, no espaço e entre setores; e consistentes com os resultados das Contas Nacionais.
Esse sistema específico de informações, em apoio à avaliação do impacto socioeconômico do turismo, deve abranger um conjunto de áreas, interdependentes, preliminarmente traduzidas em $\mathbf{5}$ (cinco) agregados:

a) Demanda: representada pelo conjunto das diferentes formas de turismo - interno, receptor e emissor -, discriminadas segundo as características dos visitantes e das viagens;

b) Produção: dada pelo resultado gerado pelo conjunto dos setores característicos, conexos e interdependentes do turismo;

c) Formação Bruta de Capital (FBK) e Inversões Financeiras: investimentos efetuados para ampliar o estoque de capital e a produção de setores produtivos característicos, conexos ou complementares do turismo;

d) Outros Indicadores: constituídos de medidas físicas, não monetárias; de informações do emprego; da discriminação dos componentes importados, do consumo turístico nacional; dos componentes exportados, do consumo do turista nacional no exterior; entre outros;

e) Avaliação do Impacto: indicadores de avaliação dos efeitos do turismo nos agregados macroeconômicos: na geração do PIB, na arrecadação de impostos, na geração de empregos, na FBK, entre outros.

\section{Resultados disponibilizados pela CST}

Como decorrência da elaboração da CST, pode-se dispor dos seguintes resultados:

a) Agregados Macroeconômicos: valor agregado e PIB turísticos;

b) Consumo Turístico: discriminado por fonte de suprimento, oferta interna ou exportação;

c) Conta Produção, por ramo de atividade, incluindo dados de Emprego, Relações Intersetoriais e FBK;

d) Outras Informações relevantes à construção de modelos de avaliação dos impactos do turismo;

e) Indicadores de Caracterização do Turismo, baseados em números de chegadas; forma de viagem; duração; motivo; modo de transporte; meio de hospedagem; destino; procedência; etc.

Além desses resultados, a CST constitui-se em um importante instrumento de comparação dos resultados internacionais do turismo, dadas as diretrizes da 
OMT no sentido de padronizar conceitos e classificaçōes, inclusive em suas consistências com o sistema de Contas Nacionais (SNA/93).

A construção da CST é uma tarefa complexa que depende da disponibilidade de um conjunto de informaçōes inéditas em algumas localidades. A proposição metodológica admite sua implantação por etapas, recomendando as mais prioritárias. Nesse sentido, mesmo que em moldes simulados, para algumas situaçōes a construção da CST constitui-se em um procedimento "guia" na definição da escolha das variáveis essenciais, informaçōes básicas na seleção dos dados necessários para levantamento e compilação.

\section{Conceitos básicos}

Para fins de avaliação de seus impactos econômicos, conceitua-se turismo como o "conjunto de atividades que as pessoas realizam durante suas viagens e estadas em lugares distintos de seu entorno habitual, por um período de tempo consecutivo inferior a um ano, com fins de ócio, por negócios ou outros motivos" (ONU; OMT, 1994).

A estrutura da CST está baseada nas relaçōes entre a oferta e a demanda. Nesse sentido, são apresentadas a seguir as definiçōes básicas relativas ao conceito da Demanda e, posteriormente, as associadas ao conceito da Oferta.

\section{Demanda}

- Visitantes: "indivíduo que se desloca a um lugar distinto de seu entorno habitual, por um período de tempo inferior a 12 meses e cuja finalidade principal da viagem não seja efetuar uma atividade remunerada no local visitado" (OMT - 93).

- Entorno Habitual: corresponde aos limites geográficos dentro dos quais o indivíduo se desloca em sua vida cotidiana, exceto por ócio ou recreação (condição que exclui as residências secundárias do conceito de entorno habitual, mesmo que ocorram visitas regulares). Entorno habitual não é sinônimo de residência, haja vista que o local de trabalho faz parte do entorno habitual e pode ser distinto do local de residência.

- Classe de Visitantes, por duração de viagem: segundo a duração da estada, pode-se classificar os visitantes em Turistas, que permanecem uma ou mais noites no local visitado, ou Excursionistas, que compreen- dem os visitantes que não pernoitam no local visitado. Têm-se ainda os visitantes em Trânsito, que para fins da CST serão tratados como visitantes.

- Classe de Visitantes, por destino: segundo o destino das viagens, temse duas categorias de visitantes: os Internacionais - cujo país de residência é diferente do país visitado (inclui o nacional, residente no exterior) e os Internos - cujo país de residência é o próprio país visitado (inclui o estrangeiro residente).

- Consumo Turístico: "gasto total de consumo efetuado por um visitante, ou por conta de um visitante, para, durante ou decorrente de sua viagem e estada no lugar de destino" (OMT).

- Local do Consumo Turístico: podem-se distinguir sete agregados de consumo turístico, a partir do critério do local:

- C.T. Interno - efetuado por residentes em seu próprio país (inclui bens importados);

- C.T. Emissor - efetuado por residentes em países diferentes de suas residências (inclui bens nacionais, consumidos no exterior);

- C.T. Receptor - efetuado por não-residentes no país receptivo (internacional);

- C.T. Interior - compreende todo o gasto efetuado por residentes e não-residentes no país receptivo;

\section{T. Interior $=$ C. T. Interno + C. T. Receptor}

- C. Interior Turístico - acresce ao C.T. Interior os gastos do C.T. Emissor no país de origem (antes e depois);

\section{Interior Turístico $=C$. T. Interior + Parte Interior do C. T. Emissor}

- C.T. Nacional - compreende todo o consumo de residentes, independentemente do destino;

$$
\text { C. T. Nacional }=\text { C. T. Interno }+ \text { C. T. Emissor }
$$

- C.T. Internacional - compreende todo o C.T. Receptor e o C.T. Emissor.

C. T. Internacional $=$ C. T. Receptor + C. T. Emissor 
- Consumo Coletivo Turístico - compreende o consumo de uma classe de bens/serviços, que apresenta as seguintes condições especiais:

- os bens/serviços podem apresentar-se simultaneamente a todos os indivíduos (não-propriedade);

- sua utilização não requer acordo explícito ou participação ativa (passiva);

- sua utilização por um indivíduo não reduz a disponibilidade aos demais (não-rivalidade).

No caso do Turismo, constituem-se exemplos típicos:

- legislação e regulamentação da atividade;

- promoção pública da atividade;

- manutenção da ordem e da segurança;

- manutenção das áreas públicas;

- planejamento e informações, entre outros.

- Unidade de Consumo: a identificação da unidade de consumo é muito importante, pois permite controlar e identificar a cobertura efetiva do consumo. São 4 (quatro) as unidades de consumo:

- Visitante: a unidade de consumo mais relevante;

- Consumo efetuado por família residente, decorrente da estada de visitantes: o caso mais comum se refere aos gastos dos residentes na recepção de parentes ou amigos;

- Unidades produtivas, atuando como tal: empresas financiando gastos de viagens de seus funcionários em serviço;

- Administrações Públicas e congêneres: quando financiando gastos de viagens para tratamento médico, formação profissional e outros dessa natureza, consideradas transferências sociais em espécie;

- Resto do mundo: residentes em viagem a outros países, hospedados gratuitamente em residência de parentes ou amigos, caracterizando-se como transferência em espécie.

\section{Oferta}

Nem todos os bens e serviços do consumo turístico são característicos desta atividade. Convém distinguir dois tipos: bens/serviços característicos, os típicos da atividade, e bens/serviços conexos, os que são afins, mas não típicos.

\section{Tipos de bens/serviços:}

Com a finalidade de padronizar conceitos, a OMT propõe:

- Característicos: aqueles que, sem o turismo, deixariam de existir em quantidade significativa ou seu consumo reduzir-se-ia substancialmente;

- Conexos: são consumidos pelos visitantes em quantidades significativas, mas não são típicos, muito menos exclusivos;

- Específicos: o conjunto de ambos os tipos anteriores.

Por dificuldades metodológicas, é recomendável, inicialmente, restringir-se a presente análise às atividades de vendas dos produtos aos visitantes, deixando-se para momentos posteriores a análise das atividades que os produzem. Assim, apenas o setor Serviços será enfatizado nesta fase inicial de implantação do sistema de CST.

\section{Serviços característicos}

Entre os serviços considerados característicos, os eleitos como os mais destacados pela OMT para fins de comparações internacionais são:

- alojamento;

- provisão de alimentos e bebidas;

- transporte e serviços associados (locação de automóveis, ...);

- organização de viagens;

- guias turísticos;

- serviços recreativos e culturais, entre outros.

\section{Serviços conexos}

O conceito conexo foi recomendado para ser adotado para se referir a bens e serviços não imediatamente reconhecidos como "característicos" do turismo, mas que, ainda assim, apresentam destacadas relações com esta atividade, variando o seu grau de importância em função das peculiaridades de cada localidade turística. Entre os serviços conexos, têm-se:

- táxis;

- artigos de artesanatos, "souvenires", etc.;

- restaurantes, entre outros. 


\section{Ramos de atividades turísticas}

Seguem os conceitos das Contas Nacionais, conforme estabelecido em SNA93. A unidade estatística é o estabelecimento, produtor de uma atividade principal. Segundo a SNA-93, ramo de atividade é constituído por "grupos de estabelecimentos dedicados à mesma classe de atividade produtiva".

A produção dos ramos de atividades fica mais bem descrita, discriminando-se a sua composição por produto; dos insumos, por produto; e a remuneração dos fatores de produção.

\section{Valor agregado}

A importância econômica de uma atividade é mais bem avaliada quando analisada no conceito de valor agregado (V.A.), que assegura a não-duplicidade de contagem.

V. A. Bruto $=$ V. Produção - V. Consumo Intermediário

V. A. Líquido = V. A. Bruto - V. Consumo do Capital Fixo (Depreciação)

\section{Emprego}

Trata-se de uma variável de importante significado social e econômico. Em geral, as atividades relacionadas com o turismo são intensivas em mão-de-obra.

São também desejáveis as disponibilidades de outras características: sexo, idade, nacionalidade, escolaridade, salário, ocupação, tamanho do estabelecimento, entre outras.

A questão do emprego, no caso do turismo, apresenta uma particularidade ressaltada: a sazonalidade no uso de mão-de-obra, em resposta às flutuações de demanda.

\section{Formação bruta de capital (FBK)}

Importante indicador para descrever com antecipação os resultados da oferta turística, tanto de bens/serviços específicos, como os relacionados.

No caso do turismo, reveste-se de significado especial pela importância da infra-estrutura básica no seu desenvolvimento, como Aeroportos, Rodovias, Ferrovias (em Transportes); Hotéis, Restaurantes, Bares e Similares (nas áreas de Hospedagem, Alimentação e Bebidas); Recreação, etc.
A dificuldade consiste em se "isolar" a contribuição da atividade turística na efetivação desses tipos de investimentos.

\section{Método e Estrutura}

O marco conceitual da CST nada mais é do que um conjunto de definições e classificações, consubstanciadas e integradas em tabelas organizadas de uma forma lógica e consistente, que permite examinar, de forma periódica, os principais aspectos econômicos da atividade de turismo. Os seus resultados são traduzidos em um conjunto de dez tipos de tabelas padronizadas, que contempla aqueles conceitos e classificações.

Os seis primeiros tipos de tabelas envolvem informações de consumo e produção das atividades de turismo, assim distribuídos: os quatro primeiros tipos envolvem informações de consumo turístico, por tipo de produtos e formas de turismo; o quinto tipo abrange dados de produção e da estrutura produtiva das atividades turísticas; e o sexto tipo consolida e confronta os dados de consumo e de produção, possibilitando o cálculo do valor adicionado e do PIB turísticos, bem como dos seus componentes.

Nos demais quatro tipos são levantadas informações que revelam outros aspectos dessa atividade, assim discriminados: no sétimo tipo aparece o emprego gerado; no oitavo a formação bruta de capital fixo (FBK); no nono tipo o consumo dos chamados serviços públicos de turismo, tais como os de planejamento, coordenação, controle, fiscalização, geração de estatísticas do setor; e no décimo e último tipo um conjunto de indicadores físicos que possibilitam obter uma radiografia geral das principais características da atividade (números e tipos de turistas, tipos de transporte utilizados, características dos alojamentos oferecidos, etc).

Como se nota, trata-se da implantação de um sistema de informações nada desprezível, não só pela diversidade e volume das informações requeridas, mas, sobretudo, pelo seu caráter de perenidade, ou seja, de acompanhamento estatístico sistemático e permanente do comportamento do setor de turismo.

A tarefa de implantação completa desse sistema de informações é complexa e está prevista para ser feita em etapas, dado que demanda tempo e esforços conjugados das várias instituições que, direta ou indiretamente, geram as informações relativas ao setor de turismo.

Este trabalho da Fipe, ora descrito, constitui-se na primeira dessas etapas de implantação da CST no País. Ao perseguir o seu principal objetivo de gerar, 
para um dado ano, o referido conjunto de tabelas da CST relativas ao Brasil, ela também irá propiciar o levantamento das informações sobre turismo disponíveis no País e os resultados da análise da compatibilidade de conceitos e de classificações entre elas - de acordo com a base metodológica da CST -, de modo a possibilitar a identificação das adaptações que serão exigidas nos dados que já são atualmente levantados, bem como indicar as lacunas que terão que ser preenchidas para se atingir a plena implantação da CST.

Isto posto, apresentam-se a seguir algumas características das principais variáveis utilizadas neste estudo, bem como de suas fontes básicas de informação.

\section{Fontes de Dados: descrição e restrições}

Como visto, a CST é concebida para ser parte integrante das Contas Nacionais do país em consideração. Sendo assim, no caso do Brasil, a principal fonte dos dados é o IBGE, que é a entidade responsável pela elaboração não só das Contas Nacionais, mas também dos principais indicadores dos níveis de atividade dos diferentes setores produtivos da economia brasileira.

\section{Contas Nacionais}

No que se refere às informações das Contas Nacionais, com base nos últimos dados divulgados de 1998 é possível constatar que o nível de agregação da mesma é muito excessivo para o caso das atividades turísticas. Apenas o grupo de bens e serviços denominado "Alojamento e Alimentação" aparece de forma isolada dentro do item "Serviços Prestados às Famílias". Por esta razão - nível excessivo de agregação das atividades turísticas na composição das Contas Nacionais -, reduz-se a possibilidade de sua plena utilização. Ainda assim, constitui-se na mais relevante fonte de dados disponíveis, destacando-se a sua contribuição na indicação dos valores referenciais dos agregados nacionais, como delimitadores dos valores estimados, pelos métodos alternativos adotados, assegurando a melhoria de sua consistência com os resultados daqueles agregados.

\section{Pesquisa Anual de Serviços - PAS}

Afora as informações fornecidas pelas Contas Nacionais, outra importante fonte de dados para a finalidade desse estudo, também do IBGE, é a Pesquisa
Anual de Serviços, concluída em outubro de 2001, para os anos de 1998 e 1999, e depois atualizada. Esta Pesquisa envolve informações do conjunto das empresas prestadoras de todos os tipos de serviços, constantes da Classificação Nacional de Atividades Econômicas (CNAE).

Merece ressalva o fato de que o levantamento de dados desta pesquisa do IBGE restringe-se às empresas formalmente constituídas, não contemplando, portanto, a economia informal deste setor, o que requer que se promovam ajustes metodológicos para sua generalização. Mesmo com esta restrição, pelo nível de informações disponibilizadas pela PAS, deve-se ressaltar que esta Pesquisa do IBGE constitui-se, de fato, na mais importante fonte de dados para a construção da CST no Brasil, principalmente no que se refere às informações da oferta dos bens e serviços ligados ao turismo.

A Pesquisa insere-se no modelo de pesquisas anuais de caráter estrutural, em substituição aos Censos Econômicos. Na verdade, no que se refere aos Serviços, os últimos levantamentos estatísticos abrangentes foram realizados em 1985 (Censos) e em 1994 (pesquisa Censo Cadastro).

Trata-se de um setor que engloba uma ampla gama de atividades, correspondendo a várias seções da Classificação Nacional das Atividades Econômicas CNAE.

A Pesquisa se propõe a construir "um sistema de informações que permita a elaboração de estimativas de valor adicionado, emprego e salário, em níveis detalhados da CNAE e por Unidades da Federação...; fornecer as informações necessárias ao tratamento dos segmentos produtivos cobertos pela pesquisa no Sistema de Contas Nacionais; e atualizar o Cadastro Central de Empresa Cempre....."

O segmento de empresas com 20 ou mais pessoas ocupadas teve tratamento censitário, o que permite a divulgação de dados num nível mais detalhado, de 4 (quatro) dígitos.

\section{Pesquisas de Orçamentos Familiares - POF}

Ainda no âmbito do IBGE, foi utilizada uma outra importante fonte de dados para este estudo, constituída pelas Pesquisas de Orçamentos Familiares (POF). Sua última versão envolveu o levantamento pormenorizado de dados de despesas, de recebimentos e de diversas características de 16.013 domicílios selecionados em 11 sub-regiões do País - as Regiões Metropolitanas de Belém, Fortaleza, Recife, Salvador, Belo Horizonte, Rio de Janeiro, São Paulo, Curitiba, Porto 
Alegre, Distrito Federal e o município de Goiânia - ao longo do período de $1^{\circ}$ de outubro de 1995 a 30 de setembro de 1996.

Tendo em vista que essa pesquisa se baseou numa classificação de 3.285 tipos de despesas e de recebimentos das famílias, ela fornece um bom nível de detalhamento das estruturas de consumo familiar por regiões do País, inclusive daquela parte que interessa particularmente ao presente estudo, qual seja, a dos itens relativos às despesas com bens e serviços associados às atividades de turismo.

Mas para isso foi necessário trabalhar-se com os chamados microdados dessa pesquisa, ou seja, com os dados primários dos questionários aplicados aos domicílios pesquisados, dado que as informações já tabuladas disponibilizadas pelo IBGE envolvem um razoável nível de agregação dos bens e serviços consumidos pelas famílias.

\section{Pesquisa Fipe-Embratur}

Ainda, pelo lado da demanda, foi possível determinar importantes elementos de estimativas, utilizando-se a fonte Pesquisa Fipe-Embratur, "Caracterização e Dimensionamento do Turismo Doméstico no Brasil -2001/2002". Um desses elementos refere-se à composição dos gastos do turista doméstico, que propicia, entre outras informações, a proporção relativa dos gastos entre alojamento, transportes, passeios turísticos, compras de "souvenires", etc.

\section{Contas Satélites de Turismo no Brasil: resultados}

Apresentam-se aqui os resultados obtidos na estimação da Conta Satélite do Turismo no Brasil, com base em dados do ano de 1999. Para facilitar a sua análise e compreensão, os mesmos são organizados num conjunto de quadros resumos, que permitem uma mais clara visualização dos principais resultados agregados do setor de Turismo, bem como da sua importância em relação ao conjunto da economia do País. O conjunto dos sete quadros básicos da CST estimados para o Brasil, de acordo com a metodologia sugerida pela OMT, pode ser encontrado na referida Pesquisa da Fipe ${ }^{3}$.

3. Fipe - Fundação Instituto de Pesquisas Econômicas. 2002. Impacto Econômico do Turismo na Economia, Avaliado pela CST, Relatório de Pesquisa, São Paulo, abril.
Em relação a esses resultados, é importante destacar que, em razão de alguns problemas de disponibilidades de dados, as mesmas devem ser consideradas como estimativas conservadoras da real dimensão econômica do turismo no País, especialmente por não incluir a contribuição dos investimentos de FBK.

Em relação aos setores mais importantes do turismo, quais sejam os de alimentação, alojamento e de transportes rodoviário e aéreo, acredita-se que os resultados são os mais confiáveis, dado que nesses casos os problemas de dados foram mínimos. Contudo, em relação aos demais setores, principalmente quanto ao dos serviços de residência secundária ou gratuita, a conseqüência da deficiência de informações sempre foi no sentido da subestimação da efetiva importância econômica dos mesmos.

Em função disso, a utilização das estimativas aqui apresentadas necessita ser feita com as devidas precauções, podendo-se considerá-las como pisos inferiores dos reais níveis que cada uma delas deve ter atingido no ano de 1999.

\section{Principais resultados}

Destacando-se inicialmente as estimativas de consumo, pode-se verificar pela Tabela 1, a seguir, que o total do consumo turístico atingiu em 1999 o expressivo montante de $\mathrm{R} \$ 51,1$ bilhões, o que equivale a $\mathbf{8 , 5 \%}$ do consumo total das famílias brasileiras e a 5,3\% do PIB do País. Por outro lado, se se restringe a análise ao total do consumo interior turístico, ou seja, que considera apenas os gastos com bens e serviços realizados no País, verifica-se que o montante alcançou a cifra de $\mathbf{R} \$ 45,4$ bilhões (7,6\% do consumo total das famílias ou $4,7 \%$ do PIB). Considerando-se que a quase totalidade desses bens e serviços é produzida no País, é aproximadamente esse o volume de renda gerado, direta e indiretamente, pelo setor de turismo no País.

Quanto à contribuição dos tipos de turismo para esse consumo, verifica-se que é evidentemente o turismo interno ou interior o grande responsável, com $\mathrm{R} \$ 38,8$ bilhões, enquanto que o turismo receptor atingiu $\mathrm{R} \$ 3,9$ bilhões. No caso do turismo emissor, o total do consumo atingiu $\mathrm{R} \$ 8,4$ bilhões, dos quais $\mathrm{R} \$ 5,7$ bilhões foram gastos no exterior.

Em relação à estrutura produtiva das atividades que atendem a esses consumos turísticos, pode-se constatar inicialmente pela Tabela 2, a seguir, que, em termos agregados, os mesmos foram responsáveis pela geração direta de renda de cerca de $\mathrm{R} \$ 19,1$ bilhões em 1999, que corresponde a 2\% do PIB total do País desse ano. 
Tabela 4 Estimativa de pessoal ocupado gerado indiretamente pelo turismo.

ESTIMATIVA DE PESSOAL OCUPADO GERADO INDIRETAMENTE PELO TURISMO

\begin{tabular}{|c|c|c|c|}
\hline Setores Produtivos & $\begin{array}{l}\text { Consumo } \\
\text { Intermediário } \\
\text { (RS milhōes) }\end{array}$ & $\begin{array}{l}\text { Pessoal Ocupado } \\
\text { por RS milhão de } \\
\text { Produção }(* *)\end{array}$ & $\begin{array}{l}\text { Pessoal } \\
\text { Ocupado } \\
\text { Gerado }\end{array}$ \\
\hline Produtos da Agricultura, Silvicultura e da Pesca & 348,2 & 116,6 & 40.595 \\
\hline Indústria de Transformação (*) & $14.530,0$ & 10,8 & 156.925 \\
\hline $\begin{array}{l}\text { Outras Indústrias } \\
\text { Indústria Extrativa } \\
\text { Eletricidade, Gás e Ȧgua }\end{array}$ & $\begin{array}{r}1.032,9 \\
1.032,9\end{array}$ & 12,1 & 12.498 \\
\hline Construção Civil & 183,5 & 30,8 & 5.652 \\
\hline $\begin{array}{l}\text { Serviços } \\
\text { Serviços de Comércio, Alojamento e Alimentaçāo } \\
\text { Serviços de Transportes e Comunicaçōes } \\
\text { Serviços Empresariais } \\
\text { Serviços Coletivos, Sociais e Individuais }\end{array}$ & $\begin{array}{r}10.228,9 \\
134,2 \\
3.322,6 \\
6.013,7 \\
758,4\end{array}$ & 52,4 & 535.994 \\
\hline Total & $26.323,5$ & & 751.663 \\
\hline
\end{tabular}

(*) Inclui $\mathrm{R} \$ 5.238,9$, relativo ao valor dos bens conexos e nāo característicos consumidos, sem a margem de comércio (**) Coeficiente estimado com base nos valores de produçāo do SCN e de pessoal ocupado da PNAD, ambos de 1999

\section{Conclusões}

O método da Conta Satélite do Turismo, preconizado pela OMT - Organização Mundial de Turismo, se propõe a dimensionar e discriminar os impactos do turismo na economia, a partir de formulações e conceituações padronizadas, de modo a tornar mais comparáveis os resultados alcançados pelos países, nos confrontos turísticos internacionais.

Anteriormente a esta forma de medida, a avaliação do impacto econômico do turismo era procedida a partir da Matriz de Insumo-Produto, que é composta por um conjunto de setores produtivos que incluem as atividades turísticas, mas não permitem a discriminação de suas contribuições. Ainda agora com a Conta Satélite do Turismo, que se propõe seja desenvolvida por etapas, algumas atividades são avaliadas subordinadas a hipóteses de trabalho, em função da ausência de pesquisas que permitem estimativas mais acuradas. Especialmente nos casos das atividades conexas, como os restaurantes, por exemplo - de forte impacto no emprego e na renda -, em que se confundem os consumidores residentes e os visitantes.

Em relação aos resultados alcançados nesta etapa da construção da Conta Satélite de Turismo no Brasil, pode-se destacar:
- desconsiderando-se a Formação Bruta de Capital (FBK), o Produto do Turismo representa $2 \%$ do PIB do Brasil;

- se adicionada a contribuição da Formação Bruta de Capital (FBK), podese admitir que o turismo representa uma parcela superior do PIB, próxima de 2,5\%;

- dentre os setores de atividades, as maiores contribuições para o produto turístico são dadas por Transportes (34,8\%), destacando-se o aéreo $(17,9 \%)$ e o rodoviário (16,8\%); Alimentação (22,6\%); Hotéis e outros Serviços de Alojamento (12,9\%), entre outros;

- o número estimado de empregos gerados pelo turismo é de 2,4 milhões, representando 3,3\% da População Economicamente Ativa empregada, sendo 1,63 milhão diretos e 750 mil indiretos;

- sendo o Consumo Interior Turístico de $\mathrm{R} \$ 45,36$ bilhões e o Produto Turístico de R $\$ 19,08$ bilhões, a preços de 1999, pode-se inferir que o multiplicador de consumo do turismo é de 2,4 ;

- assim, considerando-se os efeitos diretos e indiretos das atividades turísticas, a participação do turismo é de $\mathbf{4 , 8} \%$ do PIB do País.

\section{Referências Bibliográficas}

CANADIAN TOURISM COMMISSION. 2001. Cuentas satélite de turismo: cifras fiables para decisiones acertadas. In: CONFERENCIA DE VANCOUVER. Resenha e Coletânea de artigos apresentados (2 v.). Canadá, maio.

DI LEO, Federico. 2001. Tourism satellite account: Italy's approach. Roma: Departamento de Integraçāo de Padronizaçāo Técnica (Istat).

FIBGE. 2001. Pesquisa anual de serviços: 1998-1999, Rio de Janeiro, v. 1.

INSTITUTO BRASILEIRO DE TURISMO (Embratur). 1991. Métodos de Estimativa na Economia Brasileira. Brasília: Embratur. (trabalho mimeografado)

INSTITUTO NACIONAL DE ESTADISTICA, GEOGRAFIA E INFORMÁTICA. 1999. Sistema de cuentas nacionales de México - cuenta satélite del turismo de México: 1993-1996. México. LIBREROS, Marion Pinot. 2001. ¿Qué aporta el SCN a la CST y viceversa? ¿Qué tipo de colaboración puede existir entre ambos sistemas?. Bruxelas: Consultora da OMT.

ORGANIZAÇÃO MUNDIAL DO TURISMO (OMT). 1999. Conta satélite do turismo (CST): quadro conceptual. Madrid: OMT.

1999. Orientaciones generales para la elaboración de la cuenta satélite de turismo (CST): medición de la oferta turística. Madrid: OMT, v. 1

1999. Orientaciones generales para la elaboración de la cuenta satélite de turismo (CST): medición de la demanda turística. Madrid: OMT, v. 2. 
2000. Recommendations on Tourism Statistics, series M, New York, $n^{2} 83$ (Rev-1.0). RABAHY, Wilson Abrahão; REJOWSKI, Miriam. 2001. Experiência brasileira em contas nacionais. Turismo em Análise, São Paulo: ECA/USP, v. 12, n 2, novembro.

SERVICIO NACIONAL DE TURISMO - CHILE (SERNATUR). 1999. Cuenta satélite del turismo em Chile (año base 1996). Santiago do Chile: Ministério de Economia, Fomento e Reconstrução do Chile.

Recebido em 08/03/2003

Aprovado em 27/03/2003 